\title{
Food court, bullying, cientista político: manifestaciones del inglés en prensa en español* $^{*}$
}

\author{
Food Court, Bullying, Political Scientist: Evidence of English in \\ the Spanish Language Press
}

Constanza Gerding-Salas ${ }^{* *}$, Paola Cañete-González ${ }^{* * *}$, Carolin Adam ${ }^{* * *+}$

\begin{abstract}
RESUMEN
Las nuevas formas de intercambio social y comercial han evidenciado el uso de préstamos del inglés en prensa en español; de allí el interés por estudiar la neología léxica que deriva de esta lengua. En este trabajo se abordan tres subtipos de formaciones anglicadas: préstamos, sintagmas híbridos y calcos. El corpus se formó con unidades léxicas extraídas de prensa chilena observada durante 12 años. La recopilación se realizó de forma manual y semiautomática, y el criterio empleado fue la neologicidad lexicográfica. Los neologismos fueron caracterizados según distintos aspectos, entre ellos, su formación y los ámbitos de mayor ocurrencia. Los resultados mostraron una presencia importante de los tres subtipos de formaciones anglicadas, especialmente en ámbitos de innovación e intercambio. Además, se constató
\end{abstract} Palabras clave: neología léxica, préstamo del inglés, sintagma anglicado, calco, prensa.

Este artículo expone resultados de una investigación adscrita al Observatori de Neologia (OBNEO), proyecto internacional e interuniversitario de investigación en neología léxica del español y el catalán, liderado por la Universidad Pompeu Fabra de Barcelona. Además, a nivel nacional, el proyecto cuenta con el respaldo institucional de la Dirección de Investigación de la Universidad de Concepción, Chile (TermUdeC, código: 03.F5.01).

*2 Chilena. Doctora en Educación de la Universidad de Concepción y Stockholms Universitet. Académica de la Universidad de Concepción, Concepción, Chile. constanza. gerding@gmail.com

*** Chilena. Doctora en Comunicación Lingüística y Mediación Multilingüe de la Universidad Pompeu Fabra. Académica de la Universidad de Concepción, Concepción, Chile.pcanete@udec.cl

Alemana. Doctora en Lingüística de la Universidad de Concepción. Académica de la Universidad de Concepción, Concepción, Chile. cadam@udec.cl 
la tendencia a no modificar ortotipográficamente estas piezas léxicas.

\begin{abstract}
The prevailing forms of social and commercial exchange have made English loanwords evident in non-specialized Spanish language press, generating interest in studying the different forms of Anglicized lexical neology. This paper deals with three subtypes of Anglicized formations in Spanish: loanwords, hybrid phrases and calques. The corpus consisted of lexical units extracted from Chilean newspapers observed over a period of twelve years. The compilation was done both manually and semi-automatically. The criterion used was that of lexicographical neologicity. The neologisms were characterized according to their formation, grammatical category, among others. The presence of the three subtypes of Anglicized formations was very high, especially in areas of innovation and exchange. In addition, the study confirmed the tendency to not modify these lexical pieces typographically.
\end{abstract} Keywords: lexical neology, English loanword, Anglicized phrase, calque, press. 


\section{Introducción}

El presente trabajo forma parte de las investigaciones realizadas en el marco del proyecto internacional para el estudio de la neología léxica del español, Antenas Neológicas-Red de neología del español, fundada en 2002 y liderada por el Observatori de Neologia de Barcelona, OBNEO. El objetivo de esta red, formada por centros de investigación de Argentina, Chile, Colombia, España, México y Perú, es describir las manifestaciones de los neologismos en diferentes variedades del español, observados principalmente en prensa escrita no especializada. El propósito es constatar la vitalidad de la lengua mediante un corpus de neologismos de distintas variedades del español, analizar los recursos que se utilizan para la innovación del léxico, difundir las nuevas creaciones léxicas, contribuir a la actualización de diccionarios (Antenas Neológicas-Red de neología del español, 2017) y aportar a la praxis de profesionales cuya herramienta de trabajo es la lengua española, a saber, periodistas, traductores, docentes e investigadores, entre otros.

En esta red se analiza la presencia de nuevas voces en el español sobre la base del protocolo denominado Metodología del trabajo en neología: criterios, materiales y procesos instrumento creado por el OBNEO (2004), que establece los criterios para la detección y clasificación de neologismos según diversos procesos. En primer lugar, este documento presenta las unidades léxicas formadas con recursos propios del español, como los neologismos creados mediante afijación, composición nominal, composición culta, lexicalización, conversión sintáctica, sintagmación, procesos de truncación y resemantización, por nombrar los más frecuentes. En segundo lugar, hace referencia a unidades léxicas incorporadas desde otras lenguas y, por tratarse de observación en textos periodísticos escritos, el OBNEO las circunscribe esencialmente a los préstamos adaptados y a los préstamos no adaptados ortográficamente. Por último, contempla una clasificación de unidades léxicas difíciles de etiquetar, como creaciones ex nihilo, cultismos o palabras dialectales y argóticas.

Dada la incidencia en español de piezas léxicas provenientes de otras lenguas, este trabajo se centró en el segundo proceso: el préstamo en general y el préstamo del inglés en particular. En efecto, como plantea Alba (2007), uno de los mecanismos frecuentes con el que las lenguas amplían y enriquecen su caudal léxico es mediante la incor- 
poración de préstamos, que son unidades léxicas que llegan a una lengua como resultado del contacto o de las relaciones de los hablantes con otras lenguas a lo largo de la historia, fenómeno natural del que el español no está exento. Guerrero Ramos (2013) complementa esta idea señalando que "los préstamos, aunque con las reticencias lógicas por el empobrecimiento o arrinconamiento que el léxico patrimonial pueda sufrir, siempre han estado presentes en las lenguas" (p. 115). Es más, los préstamos integrales pueden sufrir un proceso de adaptación que va desde la incorporación del extranjerismo crudo hasta el momento en que su uso hace que origen pase inadvertido para los hablantes. En algunas ocasiones se presentan propuestas desde la Academia con las que los hablantes no siempre concuerdan $\mathrm{y}$, como el uso suele explicarlo, son ellos los que "en determinadas ocasiones tienen, de modo inconsciente, la última palabra" (Prat Sabater, 2016, p. 261).

Si bien los préstamos lingüísticos que ha incorporado el español a su acervo lingüístico provienen de diversos orígenes, la adopción y adaptación de préstamos del inglés se han visto favorecidas en décadas recientes por el impacto global de esta lengua y de la cultura estadounidense en otras lenguas y culturas, como lo han refrendado trabajos de diversos autores (Alfaro, 1984; Castañón Rodríguez, 2009; Delgado Álvarez, 2005; Diéguez, 2004; Gómez Capuz, 2009; Haensch, 2005; Márquez Rojas, 2006; Morin, 2006; Sáez Godoy, 2005). De hecho, dada la prevalencia y la recurrencia en español de préstamos anglicados con y sin adaptación -como se ejemplifica en GerdingSalas, Fuentes, Gómez y Kotz (2012b) (biodiésel, blog, online, ránking, mall, pendrive, podcast, all inclusive, six pack, spam, retail, airbag)-, la Antena Chilena de Neología de la Universidad de Concepción (AChN-UdeC) ha centrado una parte de sus estudios recientes en estas formas de innovación léxica (Fuentes, Gerding \& Kotz, 2011; Gerding Salas, Fuentes Morrison \& Kotz, 2012a; Gerding et al., 2012b; Gerding, Fuentes, Gómez \& Kotz, 2014). Estos estudios se han realizado a partir de corpus de prensa escrita no especializada, editada en formato convencional y digital. Estos medios periodísticos, como plantea Ortega (2001), constituyen una fuente fecunda para la observación de la creación léxica y, como sostiene Méndez (2011), también constituyen un medio eficaz de propagación de neologismos entre 
los hablantes. De allí que la presente investigación se haya planteado conocer el estado del arte de la neología léxica con influencia de la lengua inglesa en el español, que se evidencia esencialmente en tres tipos de unidades léxicas: los préstamos del inglés, según la concepción del OBNEO (2004); los sintagmas híbridos, formados con palabras patrimoniales y préstamos; y los calcos del inglés, desde la visión de Gómez Capuz (2009):

- El préstamo es una "unidad importada de otra lengua" (OBNEO, 2004, p. 18), es decir, una voz de origen extranjero incorporada al español con o sin modificación ortográfica; se distingue así entre préstamo con adaptación y préstamo sin adaptación.

- Los sintagmas, por otra parte, son "unidades formadas por una estructura sintáctica lexicalizada" (OBNEO, 2004, p. 16), y pueden estar constituidos en su totalidad por préstamos, o bien, mediante una forma híbrida, o sea, la combinación de un elemento patrimonial y otro u otros de origen extranjero ( $p a c k$ de cerveza, doble pack de filtro charger).

- El calco corresponde a la traducción literal de una palabra o frase. A juicio de Gómez Capuz (2009), el calco puede ser léxico o semántico. El calco léxico o estructural es

la sustitución de una palabra polimorfemática (...), por medio de morfemas (...) ya existentes por sí solos en la lengua receptora, de manera que la unión de estos elementos dé lugar a una expresión polimorfemática (...) desconocida antes en esta lengua (Gómez Capuz, 2009, s/p).

Ejemplos de calcos estructurales son unidades como las siguientes: estación de servicio, hacerle algo sentido a alguien, píldora del día después. El calco semántico, por otra parte, "se limita a modificar el significado de una palabra ya existente en la lengua receptora" (Gómez Capuz, 2009, s/p). Ejemplos de calcos semánticos se presentan a menudo en el lenguaje de la computación: mouse / ratón, window / ventana, hard drive / disco duro. Según el mismo autor, los calcos léxicos pueden subdividirse en calcos léxicos literales (money laundering / lavado de dinero) y calcos léxicos aproximados (money laundering / blanqueo de dinero). Por otra parte, los calcos semánticos pueden ser paronímicos - también conocidos como falsos amigos-, por ejemplo assume / "asumir", en lugar de "suponer", "deducir"; y no paronímicos, 
es decir, donde la similitud con una palabra de otra lengua es conceptual, no formal: file / archivo.

La aceptación de piezas léxicas anglicadas se ha visto favorecida por la adopción, en diversos países, del paradigma de economía neoliberal con base en modelos estadounidenses que abogan por una amplia liberalización de la economía y por el libre comercio, lo que ha traído aparejada la apertura de la actividad económica y comercial al mundo globalizado (Gerding et al., 2014). Además, a esta aceptación general de léxico anglicado ha contribuido también el desarrollo vertiginoso de la ciencia, la tecnología y las comunicaciones y el estatus del inglés como lengua de prestigio (Delgado Álvarez, 2005; Guerrero Ramos, 1997; Gerding et al., 2012a; Gerding et al., 2014). De hecho, entre las razones por las cuales se produce la incorporación de léxico anglicado se suelen aducir con frecuencia el propósito de llenar vacíos denominativos, la necesidad de conseguir una comunicación diligente y eficaz, la economía lingüística y el uso jergal (Diéguez, 2004; Gerding et al., 2014; Millán Loreto, 2004).

En este contexto, el objetivo de este trabajo fue analizar las características más relevantes de la innovación léxica en la variante chilena del español desde la perspectiva del léxico anglicado en algunas de sus tres manifestaciones más frecuentes. Lo que se buscó con este análisis fue describir la configuración de las unidades objeto de estudio, así como identificar los ámbitos específicos en que se usan y las razones por las que se emplearían en la prensa, con el fin de sensibilizar a los profesionales de la lengua respecto de la presencia de estas formas de innovación frecuentes en el español actual.

\section{Metodología}

Como fuentes de recopilación de neologismos en la prensa chilena se eligieron los periódicos El Mercurio, El Sur, Las Últimas Noticias y The Clinic. Los criterios para la selección de estas fuentes de recopilación fueron los siguientes:

- que fueran periódicos de circulación nacional (El Mercurio, Las Últimas Noticias y The Clinic) y local (El Sur);

- que el formato de los periódicos seleccionados incluyera ediciones digitales como también en soporte de papel; y 
- que abarcaran una diversidad de registros lingüísticos (Las Últimas Noticias y The Clinic presentan artículos con un registro lingüístico más informal que los otros periódicos) y de orientaciones ideológicas (El Mercurio y The Clinic representan posturas ideológicas reconocibles y opuestas).

La recopilación de neologismos se realizó de forma manual y semiautomática, y las unidades léxicas se almacenaron en un banco de datos (Banco de datos del OBNEO, BOBNEO, 2017). Los datos de cada neologismo se ingresaron a fichas neológicas que se administran en una plataforma en línea (OBNEO, 2004) y el procedimiento para el vaciado es similar al del vaciado de fichas lexicográficas: se presentan diversos campos por llenar, que cubren los aspectos formales, lingüísticos y culturales-contextuales. La recopilación semiautomática, realizada mediante la herramienta Buscaneo (OBNEO, 2004), consiste en la extracción de neologismos de las ediciones en línea de las fuentes ya mencionadas. Esta fase se realizó de forma automática mediante el contraste de las unidades con el corpus lexicográfico de exclusión incorporado. Sin embargo, este mecanismo suele recoger candidatos que no corresponden a unidades neológicas propiamente dichas, como algunos nombres propios y errores ortotipográficos, entre otros, los que el neólogo debe depurar.

El proceso manual de recopilación, por su parte, consiste en la revisión de periódicos en soporte de papel, realizado por las investigadoras, proceso durante el cual se extraen de estas fuentes las unidades que se consideran neológicas, sobre la base de criterios de neologicidad previamente establecidos. Cabré (1993) plantea que existen diversos criterios, entre los cuales los tradicionales son el diacrónico, el de inestabilidad formal o semántica, el psicolingüístico y el lexicográfico. Según la autora, ninguno de los cuatro criterios es, por sí solo, definitivo para el reconocimiento de unidades nuevas $\mathrm{y}$, a falta de un criterio único, objetivo y sistemático, los neólogos suelen optar por el parámetro lexicográfico.

Para la observación neológica que realizan las Antenas Neológicas son preponderantes los criterios psicolingüístico y lexicográfico (OBNEO, 2004). El primero se funda en el "sentimiento de neologicidad" (Sablayrolles, 2000), que se refiere a la intuición que tienen los hablantes acerca de la condición de nuevas palabras que apa- 
recen en su propia lengua, sentimiento que suele ir disipándose a medida que las voces se arraigan en el repertorio de los hablantes. El segundo criterio alude a la condición de neológica de una unidad léxica potencialmente nueva, cuando se constata que no figura registrada en una batería lexicográfica previamente definida como corpus de exclusión. Dicha condición desaparece cuando la unidad es incorporada a una de estas obras lexicográficas de referencia (Cabré, 1993). Este último parámetro complementa el criterio psicolingüístico, por cuanto permite a todos los integrantes de la red homogeneizar la detección de las unidades léxicas y establecer su carácter neológico de manera objetivable.

El corpus de exclusión estuvo constituido por el Diccionario de uso del español de América y España (Battaner, 2002) y el Diccionario de la lengua española (Real Academia Española, RAE, 2016). Ambas obras forman parte del repertorio lexicográfico de exclusión del OBNEO, por ser representativas de los diccionarios actuales de amplia divulgación en círculos de habla hispana, porque ponderan el uso por sobre la norma y porque ambos poseen formato de papel y digital o en línea, lo que facilita las constataciones.

Para el caso específico de los sintagmas anglicados, los criterios utilizados para determinar el estatus de unidad léxica híbrida, préstamo o calco fueron la competencia lingüística del español y del inglés de las investigadoras, su intuición lingüística (impresión de estar ante una traducción literal o una anomalía) y la comprobación de la pertinencia del criterio intuitivo mediante documentación escrita en sitios web confiables. En estos casos, se usó también un corpus lexicográfico de referencia en inglés de consulta en línea, compuesto por las obras Merriam-Webster Dictionary and Thesaurus (s/f, con la impronta de la variedad "estadounidense estándar" del inglés), Free online English dictionary from Oxford dictionaries (s/f, con el sello de la variedad "británica" del inglés, aunque esta obra consigna también usos del inglés estadounidense) y WordReference (2016). Esta última fuente lexicográfica se usó por sus características de diccionario bilingüe, actualizable y con foro de discusión, lo que resultó particularmente útil para desentrañar el sentido de unidades neológicas anglicadas escasamente documentadas, por ser de uso muy reciente. 


\section{Resultados y discusión}

Los análisis realizados permitieron observar distintas características de las piezas léxicas anglicadas en su manifestación en la prensa.

En primer lugar, se observó que de un corpus constituido por 15.996 unidades léxicas neológicas de variados tipos de formación (BOBNEO, 2017) los préstamos, en general, representaron prácticamente el $30 \%$ $(\mathrm{N}=4.747)$ y que de ese porcentaje el $80 \%(\mathrm{~N}=3.838)$ correspondió específicamente a formaciones anglicadas (Banco de datos del Observatori de Neologia, 2017). El segundo lugar en cuanto a presencia en la prensa lo ocuparon los préstamos provenientes del francés (crutón, déjà vu) y el tercero, los préstamos del italiano (a capella, risotto), ambos con muy escasa presencia ( $7 \%$ y $3 \%$, respectivamente).

La alta frecuencia de unidades anglicadas en la prensa obedecería, por un lado, al influjo político, económico y cultural de Estados Unidos en la sociedad chilena actual, lo que se traduciría en una relativa soltura por parte de los hablantes para incorporar préstamos del inglés cuando las creaciones nuevas aún carecen de denominación en español (youtuber, cameo, Bluetooth) o en una marca de prestigio que los hablantes atribuirían al uso de voces anglicadas (app, after office, hacer sentido). Por otro lado, la adopción de voces de origen anglicado en la prensa estaría influida también por la urgencia de trasvasar al español mensajes originalmente redactados en inglés (lavado de dinero, tarifa plana, pantalla touch) y por el empleo de vocablos cortos, propios de la funcionalidad del estilo periodístico (wifi, mall, food court).

Respecto de la adaptación de anglicismos, se determinó que apenas el 8\% evidenció algún tipo de modificación ortográfica al ser empleados por los redactores de prensa. De este resultado se puede colegir que en Chile no habría una intención de naturalización o adaptación ortográfica de los préstamos, cuestión que se ha observado también en estudios anteriores (Diéguez, 2004; Gerding et al., 2012a; Gerding et al., 2014). Los préstamos del inglés que sufren adaptación ortográfica, por lo general, exhiben una alteración menor en su escritura (por ejemplo: ciberbullying, pendrive, ránking, reggaetón). Los préstamos sin adaptación corresponden a variados ámbitos y son de uso recurrente en la prensa estudiada (por ejemplo: coach, retail, selfie, smartphone, 
six-pack, bluetooth, blue-ray, coffee break, cupcake, bullying, trailer, casting, delivery, kickboxing, crossfit, crowdfunding, merchandising).

A modo de confirmación, fue interesante constatar que el uso de préstamos inalterados del inglés es omnipresente en la prensa de todos los países que conforman la red Antenas Neológicas (Gerding et al., 2012b). Sin embargo, es importante mencionar que cada variante de la lengua exhibe una proporción variable de préstamos y su incorporación no siempre es coincidente de un país a otro, como ocurre, por ejemplo, con la denominación del dispositivo portátil que se emplea para almacenar datos y trasladarlos de un computador a otro. Algunas denominaciones de este dispositivo corresponden a un préstamo directo del inglés (pendrive, pen drive, memory stick), otras a préstamos híbridos (memoria flash, memoria usb, llave usb, lápiz usb), otras a una traducción literal o calco (lápiz de memoria) y otras a formaciones más creativas en la lengua receptora (memoria portátil, llave maya).

En cuanto a la presencia de unidades sintagmáticas neológicas anglicadas en el español de Chile, se determinó que del total de sintagmas registrados, el $23 \%$ correspondía a unidades anglicadas. La mayor parte estaba formada por calco anglicado (86\%), como por ejemplo, "cientista político", cuya denominación ("politólogo") se encuentra documentada en el Diccionario de la lengua española (2016). Los sintagmas híbridos, por su parte, como "horario prime" en lugar de "horario de máxima audiencia" (WordReference, 2016), solo tuvieron una representación del $14 \%$.

Respecto de los sintagmas formados por calco anglicado, se observó una fuerte predominancia de los calcos léxicos frente a los calcos semánticos ( $82 \%$ y $18 \%$, respectivamente). En la primera categoría destacaron los calcos léxicos literales, con una recurrencia del $80 \%$ (por ejemplo, "dispositivo vestible", traducido literalmente de wearable device; "patio de comida(s)", de food court, y "efecto invernadero", de greenhouse effect). En cambio, los calcos léxicos aproximados representaron solo el $2 \%$ y, en estos casos, la adaptación podría deberse a matices culturales, como en "píldora del día después", proveniente de morning after pill y "patio gastronómico" o "plaza de comida" y food court, o bien, a algún grado de economía lingüística, como en "anticonceptivo de emergencia" para emergency contraceptive pill, donde se omite la palabra "píldora". 
Por otra parte, el $8 \%$ correspondió a calcos semánticos del tipo paronímico, mientras que el $10 \%$ a los de tipo no paronímico. En el primer grupo se encontraron unidades como "orgánico, ca", tomado del inglés en el sentido de "sin agroquímicos" (como en "café orgánico") y "dramático, ca”, cuyo significado en español es "teatral, afectado, relativo al drama o capaz de interesar y conmover vivamente" (Diccionario de la lengua española, 2016), pero ha ingresado a esta lengua con el sentido anglicado de "drástico, ca" (como en la "dramática alza" del dólar). La aceptación de elementos como “orgánico, ca” y “dramático, ca”, de los que el hablante común no parece advertir su carácter neológico en español, respondería naturalmente al parecido formal de estas voces en ambos idiomas. En cuanto al grupo de calcos semánticos no paronímicos, se observó la traducción literal del significante, como en el caso de "blando, da" para el adjetivo soft en sintagmas como "habilidades blandas" o "competencias blandas" (términos provenientes de la psicología organizacional y que se refieren a "habilidades sociales") o “plano, na”, para el adjetivo flat, con el nuevo sentido de "fijo, ja”, como en "tarifa plana” (cuyo significado anglicado implica "sin variación”).

En lo que respecta a las formaciones sintagmáticas híbridas, se observó que su estructura respondía a distintos mecanismos combinatorios, siendo el más frecuente el de una voz patrimonial seguida de un préstamo intacto (como en "pantalla touch" o "pagar online"). También se comprobó que las unidades anglicadas coexisten con sintagmas patrimoniales (por ejemplo, "hora peak" con "hora pico" u "hora punta”), incluso en una misma fuente de recopilación, y su uso podría estar determinado por razones de estilo, de variante diatópica o de preferencia del redactor.

Adicionalmente, se comprobó que el elemento anglicado de algunas unidades híbridas tenía un equivalente documentado en español, como en el caso de "televisor inteligente" o "red inalámbrica", en lugar de "televisor smart" o "red wifi", respectivamente, pero la frecuencia de uso de la formación híbrida era mayor que la de la formación con elementos solo patrimoniales. Como ya se ha comentado, es probable que la presencia de este tipo de sintagmas en la prensa esté condicionada por el prestigio del que goza la lengua inglesa, como también por economía lingüística o por factores asociados con la contingencia, como ocurre con muchas unidades léxicas anglicadas no sintagmáticas. 
Otros aspectos observados en relación con las unidades neológicas anglicadas fueron la categoría gramatical a la que pertenecían las unidades neológicas y el uso de marcas tipográficas con que estaban etiquetadas. Por una parte, se observó que la categoría gramatical predominante fue el nombre, con una presencia superior al $80 \%$, lo que se explicaría por la necesidad de denominar las realidades nuevas a medida que estas se van creando. La alta frecuencia de la categoría nombre dice relación con la fuerte carga semántica de estas palabras lexicales. En el caso de los sintagmas anglicados híbridos y los calcos, se observó que, si bien cumplían diversas funciones gramaticales, como sintagmas adverbiales (a full), sintagmas verbales (hacer bullying) y sintagmas nominales (crossfit al aire libre, hora peak), los ítems léxicos que cumplían la función de nombre tuvieron una fuerte presencia: 80\% para los neologismos híbridos (por ejemplo, "bullying virtual", "chico reality", "secuestro express") y 84\% para los calcos neológicos (por ejemplo, "contaminación cruzada", "responsabilidad social empresarial", "tienda de conveniencia"). La presencia de formaciones híbridas y por calcos sintagmáticos verbales, adverbiales y preposicionales fue muy poco significativa $(<2 \%)$.

Por otra parte, menos del 30\% de las unidades anglicadas evidenció algún tipo de marca tipográfica que señalara su condición de extranjerismo, siendo la letra cursiva y las comillas las etiquetas más usadas. Por ejemplo, el anglicismo retail se detectó en 153 ocasiones en el período estudiado, pero solo 25 veces estaba escrito en letra cursiva y no se evidenció ningún otro tipo de marca. La inestabilidad en el uso de marcas tipográficas para un mismo anglicismo podría ser un indicio de la gradualidad del proceso de asimilación del extranjerismo en el español.

$\mathrm{Al}$ analizar las áreas temáticas en las que hubo presencia de unidades léxicas anglicadas, se observó una mayor concentración en tecnología e informática, economía y comercio, medicina y salud, medioambiente y derecho, lo que confirma los hallazgos de estudios anteriores (Fuentes, Gerding-Salas, Pecchi, Kotz y Cañete-González, 2009; Gerding et al., 2012a; Gerding et al., 2014). De acuerdo con una clasificación realizada a partir de las áreas temáticas establecidas en el Repositorio Institucional (Comisión Nacional de Investigación Científica y Tecnológica, CONICYT, 2016), en este estudio se observó que más del 
$60 \%$ de los anglicismos no adaptados se concentraba en actividades relacionadas con cuatro ámbitos principales:

- tecnologías de la información y la comunicación: e-book, hashtag, roaming;

- cultura y entretención: after hour, talk show, videogame;

- deportes: canopy, match point, running; y

- economía, comercio y finanzas: crowdfunding, factoring, retailer.

Esta marcada presencia de piezas léxicas anglicadas en dominios específicos podría deberse, en primer lugar, a la escasez de manuales, aplicaciones y etiquetado de productos en ciertos ámbitos traducidos al español, como el computacional, por ejemplo, donde mucha información está disponible principalmente en inglés, razón por la que el léxico ingresaría de forma directa, contribuyendo así a la incorporación de términos anglicados. Adicionalmente, la información escrita en inglés en internet supera ampliamente a la que circula en español, por lo que muchas veces se recurre a anglicismos para llenar vacíos denominativos.

En segundo lugar, muchas manifestaciones culturales (música, deportes, gastronomía, entre otros) provenientes de Estados Unidos tienen amplia acogida en Chile, especialmente entre los jóvenes, lo que provocaría el transvase de préstamos que aluden a expresiones artísticas populares y hábitos, ya sea con el propósito de llenar vacíos léxicos o por esnobismo de los consumidores de la cultura estadounidense: podcast, shoegazing, runner, crossfit al aire libre, donut, delivery).

Finalmente, es posible pensar que la influencia del inglés en el plano de la economía, el comercio y las finanzas tenga relación directa con el modelo económico de libre mercado vigente en Chile desde hace unas cuatro décadas. Como consecuencia, muchos economistas chilenos se han posgraduado en universidades estadounidenses, por lo que es frecuente que utilicen parte de la jerga de la economía directamente en inglés, o bien, que la incorporen por la vía del calco o la hibridación. Además, al ser este idioma la lengua franca de los acuerdos comerciales entre Chile y otros países, como China, India y Japón, por ejemplo, la adopción y la adaptación de préstamos puede verse favorecida. 
Contrariamente a las tendencias anteriores, se observó que la frecuencia de uso de los distintos tipos de unidades anglicadas es muy baja en la prensa en áreas como el vestuario, la moda, el turismo y la hotelería, probablemente porque los anglicismos de uso frecuente en estos rubros a menudo aparecen en publicaciones especializadas, en menús de restaurantes, en catálogos de tiendas o en folletos turísticos, más que en artículos noticiosos.

Ahora bien, entre las principales razones por las que se usarían préstamos del inglés en la prensa se podrían mencionar las siguientes: a) economía lingüística: notebook en lugar de "computador portátil", upgrade en lugar de "actualización de tecnologías de la información", sitcom en lugar de "comedia de equivocaciones"; b) prestigio social: know how en lugar de "conocimiento práctico", lodge en lugar de "hotel para excursionistas de nivel socioeconómico alto", outdoor en lugar de "al aire libre"; c) vacíos denominativos: jingle para referirse a una "canción breve y contagiosa con fines publicitarios", subprime para "crédito de alto riesgo", commodity para "materia prima semielaborada".

\section{Conclusiones}

La participación de una diversidad de países en intercambios económicos, sociales y culturales ha redundado en la necesidad de disponer de una suerte de lengua franca para el entendimiento entre personas de distintas lenguas. El idioma inglés ha servido para tal propósito y se ha convertido en lengua funcional en muchas sociedades actuales, permeándolas tanto en el lenguaje de las especialidades como también en el del léxico común. De este modo, el léxico del español se ha visto influido de manera importante por el predominio de la lengua inglesa en las comunicaciones internacionales actuales, hecho que confirman los resultados obtenidos en el presente estudio.

En general, el predominio de anglicismos obedecería a la universalidad del inglés, por efecto de la adopción de un determinado modelo de desarrollo económico y social, lo que supone distintos niveles de influencia científico-técnica y cultural. Obviamente, la incorporación de nuevas unidades léxicas anglicadas en español podría estar supeditada a una multiplicidad de razones, pero probablemente las más 
importantes sean la necesidad de llenar vacíos para la denominación de nuevos objetos, procesos o fenómenos y el prestigio que conlleva el uso de elementos anglicados. Esta influencia es palmaria en determinadas áreas del conocimiento, donde el nuevo léxico anglicado responde a innovaciones específicas. Tal como lo demostró la presente investigación, en la prensa chilena la influencia del inglés es particularmente marcada en las áreas de las tecnologías de la información y la comunicación, de la cultura y entretención, de los deportes y de la economía, el comercio y las finanzas.

En la prensa chilena, las unidades léxicas anglicadas suelen usarse sin mayores modificaciones ortográficas, posiblemente debido a la premura con que estas se van incorporando y también a la disposición de los usuarios para aceptarlas sin mayor cuestionamiento. Tampoco es muy frecuente encontrarlas marcadas tipográficamente para indicar su condición de extranjeras o de neológicas, especialmente cuando el uso se va haciendo recurrente o cuando se presume que las marcas podrían entorpecer la fluidez de la lectura. En dos estudios recientes (Gerding Salas, Cañete-González y Adam, 2018; Gerding Salas, CañeteGonzález, Adam y Blanco Correa, 2019), se indagó en las motivaciones y razones que tendrían los periodistas chilenos para optar por no modificar ortográficamente ni marcar tipográficamente las unidades anglicadas que recogen e incorporan en sus textos. Los resultados de dicho estudio han aportado información no especulativa y más precisa acerca de las razones de estas tendencias.

En cuanto a las categorías gramaticales a las que pertenecían las unidades anglicadas encontradas en la prensa chilena, tanto en este estudio como en otros anteriores (Gerding et al., 2012a; Gerding et al., 2014) se pudo constatar una fuerte predominancia de la categoría nombre, tanto para las unidades neológicas por préstamo, como para los calcos y los sintagmas híbridos. Este fenómeno debería estar asociado con la necesidad de dar nombre a realidades nuevas.

Ahora bien, los préstamos del inglés, los calcos anglicados y los sintagmas híbridos pueden variar de una comunidad hispanohablante a otra e incluso, a veces, alternar con equivalentes en español. Esta inestabilidad - que es propia de los procesos neológicos-, da cuenta de la flexibilidad que presenta el uso y de la importancia del rol de los hablantes en el uso de neologismos anglicados. 
Cabe pensar que, ante la ausencia de una política lingüística definida, los periodistas en particular y los comunicadores en general, así como también otros profesionales (profesores, traductoresy escritores, entre otros) pueden tener un papel relevante y decisivo en la incorporación o la prescindencia de léxico anglicado en el repertorio léxico de una comunidad hablante del español. De hecho, este trabajo puede aportar concretamente con trabajos interdisciplinares, talleres y coloquios a la sensibilización de académicos universitarios y profesionales de la prensa, especialmente porque la Universidad de Concepción cuenta con medios de difusión intra- y extrainstitucionales donde el objeto de estudio de este trabajo, es decir, el uso de unidades anglicadas, puede ser recurrente.

\section{Referencias bibliográficas}

Alba, O. (2007). Integración fonética y morfológica de los préstamos: datos del léxico dominicano del béisbol. RLA, Revista de Lingüística Teórica y Aplicada, 45(2), 89-109. https://doi. org/10.4067/s0718-488320070002000008

Alfaro, R. (1984). El anglicismo en el español contemporáneo. Thesaurus, 4(1), 102-128. Recuperado de https://cvc.cervantes. es/lengua/thesaurus/pdf/04/TH 04001 110 0.pdf

Antenas Neológicas-Red de neología del español. (2017). Presentación. Recuperado de https://www.upf.edu/web/antenas/presentacion

Banco de datos del Observatori de Neologia, OBNEO, BOBNEO. (2017). Ingreso. Recuperado de http://obneo.iula.upf.edu/bobneo/ index.php

Battaner, M. P. (2002). Diccionario de uso del español de América y España ( $1^{\text {a }}$ edición). Barcelona: Spes Editorial.

Cabré, M. T. (1993). La terminologia: la teoria, els mètodes, les aplicacions. Barcelona: Empúries.

Castañón Rodríguez, J. (2009). Los extranjerismos del deporte en español. Efdeportes.com, Revista Digital, 14(134). Recuperado de http://www.efdeportes.com/efd134/los-extranjerismosdel-deporte-en-espanol.htm

Comisión Nacional de Investigación Científica y Tecnológica, Conicyt. (2016). Repositorio institucional. Recuperado de http:// www.conicyt.cl 
Delgado Álvarez, A. (2005). Los anglicismos en la prensa escrita costarricense. Káñina: Revista de Artes y Letras, 29(especial), 8999. Recuperado de https://pdfs.semanticscholar.org/e447/3 8bla6f5575cd0c6e6d37c7c970e7c8332e0.pdf

Diéguez, M. I. (2004). El anglicismo léxico en el discurso económico de divulgación científica del español de Chile. Onomázein, 2(10), 117-141. Recuperado de http://onomazein.letras. uc.cl/Articulos/10/6 Dieguez.pdf

Fuentes, M., Gerding-Salas, C., Pecchi, P., Kotz, G., y Cañete-González, P. (2009). Neología léxica: reflejo de la vitalidad del español de Chile. RLA, Revista de Lingüística Teórica y Aplicada, 47(1), 103-124. https://doi.org/10.4067/s0718-48832009000100006

Fuentes, M., Gerding, C., \& Kotz, G. (2011). Loanwords in the press: The influence of English in Chile. Actas del XIX Congreso Mundial de la Federación Internacional de Traductores, 193-211.

Gerding Salas, C., Fuentes Morrison, M. y Kotz, G. (2012a). Anglicismos y aculturación en la sociedad chilena. Onomázein, 25, 139-162. Recuperado de http://onomazein.letras.uc.cl/Articulos/25/7 Gerding.pdf

Gerding-Salas, C., Fuentes, M., Gómez, L., y Kotz, G. (2012b). El préstamo en seis variedades geolectales del español: un estudio en prensa escrita. Signos, Estudios de Lingüística, 45(80), 280299. https://doi.org/10.4067/s0718-09342012000300003

Gerding, C., Fuentes, M., Gómez, L. \& Kotz, G. (2014). Anglicism: An active word-formation mechanism in Spanish. Colombian Applied Linguistics Journal, 16(1), 40-54. https://doi. org/10.14483/udistrital.jour.calj.2014.1.a04

Gerding Salas, C., Cañete-González, P., y Adam, C. (2018). ¿ Usar o no usar préstamos? He ahí la cuestión. Nueva Revista del Pacífico, 68, 42-61. Recuperado de https://doi.org/10.4067/s0719$\underline{51762018000100042}$

Gerding Salas, C., Cañete-González, P., Adam, C., y Blanco Correa, O. E. (2019). Los periodistas y su responsabilidad en la incorporación de préstamos en español. Boletín de Filología, 54(1), 231-254. Recuperado de https://scielo.conicyt.cl/scielo. php?pid=S0718-93032019000100231\&script=sci abstract

Gómez Capuz, J. (2009). El tratamiento del préstamo lingüístico y el calco en los libros de texto de bachillerato y en las obras divulgativas. Tonos, 17. Recuperado de https://www.um.es/ 
tonosdigital/znum17/secciones/tritonos-1-librosdetexto. $\underline{\mathrm{htm}}$

Guerrero Ramos, G. (1997). Neologismos en el español actual (2a edición). Madrid: Arco Libros.

Guerrero Ramos, G. (2013). El préstamo lingüístico, uno de los principales procedimientos de creación neológica. Quaderns de filología. Estudis lingüístics, 18, 115-130. Recuperado de https://dialnet.unirioja.es/servlet/articulo? codigo $=5135513$ \&orden $=0$ \&info $=$ link

Haensch, G. (2005). Anglicismos en el español de América. ELUA. Estudios de Lingüistica, Universidad de Alicante, 19, 243-251. https://doi.org/10.14198/elua2005.19.12

Márquez Rojas, M. (2006). Los anglicismos terminológicos integrales en los textos especializados del español. Estudios de Lingüistica Aplicada, 24(43), 11-29. Recuperado de https:// dialnet.unirioja.es/servlet/articulo?codigo $=6394228 \&$ orden $=0$ \&info $=$ link

Méndez, M. del C. (2011). De cómo los neologismos enriquecen la lengua. Recuperado de http://www.rionegro.com.ar/culturashow/de-como-los-neologismos-enriquecen-la-lenguaMQRN 767496

Merriam-Webster (s/f). Dictionary and Thesaurus. Recuperado de http://www.merriam-webster.com/

Millán Loreto, R. (2004). Uso de extranjerismos en la prensa venezolana y española: español o inglés, el respeto al idioma. Recuperado de http://www.ucm.es/info/especulo/cajetin/extran.html

Morin, R. (2006). Evidence in the Spanish language press of linguistics borrowings of computer and Internet-related terms. Spanish in Context, 3(2), 161-179. https://doi.org/10.1075/ sic.3.2.01mor

Observatori de Neologia, OBNEO. (2004). Metodología del trabajo en neología: criterios, materiales y procesos. Recuperado de https://repositori.upf.edu/bitstream/handle $\not 10230 / 1307 / 04$ mon009.pdf? sequence $=1$ \&isAllowed $=\mathrm{y}$

Ortega, M. P. (2001). Neología y prensa: un binomio eficaz. Espéculo. Revista de estudios literarios, Universidad Complutense de Madrid, 18. Recuperado de http://www.ucm.es/info/especulo/numerol8/neologism.html 
Oxford Dictionaries (s/f). Free online English dictionary from Oxford dictionaries. Recuperado de htstp://www.oxforddictionaries.com/

Prat Sabater, M. (2016). Proceso de integración de las incorporaciones léxicas en español: aspectos teóricos y presencia lexicográfica. Anuario de Letras. Lingüistica y Filología, 4(2), 245-295. https://doi.org/10.19130/iifl.adel.4.2.2016.1398

Real Academia Española, RAE. (2016). Diccionario de la lengua española (23a edición). Recuperado de http://www.rae.es

Sablayrolles, J.-F. (2000). La néologie en français contemporain: examen du concept et analyse de productions néologiques récentes. Paris: Honoré Champion.

Sáez Godoy, L. (2005). Anglicismos en el español de Chile. Atenea (Concepción), 2(492), 171-177. https://doi.org/10.4067/ s0718-04622005000200010

WordReference (2016). Ingreso. Recuperado de http://www.wordreference.com/ 